Henning Großkopf, Sarah Vogel, Claudia Damaris Müller, Sebastian Köhling, Jan-Niklas Dürig, Stephanie Möller, Matthias Schnabelrauch, Jörg Rademann, Ute Hempel, Martin von Bergen* and Kristin Schubert

\title{
Identification of intracellular glycosaminoglycan- interacting proteins by affinity purification mass spectrometry
}

\author{
https://doi.org/10.1515/hsz-2021-0167 \\ Received February 25, 2021; accepted July 4, 2021; \\ published online September 1, 2021
}

Abstract: Glycosaminoglycans (GAGs) are essential functional components of the extracellular matrix (ECM). Artificial GAGs like sulfated hyaluronan (sHA) exhibit pro-osteogenic properties and boost healing processes. Hence, they are of high interest for supporting bone regeneration and wound healing. Although sulfated GAGs (sGAGs) appear intracellularly, the knowledge about intracellular effects and putative interaction partners is scarce. Here we used an affinity-purification mass

Martin von Bergen and Kristin Schubert share senior authorship.

*Corresponding author: Martin von Bergen, Department of Molecular Systems Biology, Helmholtz Centre for Environmental Research GmbH - UFZ, Leipzig D-04318, Germany; and Institute of Biochemistry, Faculty of Life Sciences, Universität Leipzig, Leipzig D-04103, Germany, E-mail: martin.vonbergen@ufz.de Henning Großkopf, Department of Molecular Systems Biology, Helmholtz Centre for Environmental Research GmbH - UFZ, Leipzig D-04318, Germany, E-mail: henning.grosskopf@ufz.de. https:// orcid.org/0000-0002-5122-2477

Kristin Schubert, Department of Molecular Systems Biology, Helmholtz Centre for Environmental Research GmbH - UFZ, Leipzig D-04318, Germany, E-mail: kristin.schubert@ufz.de

Sarah Vogel, Claudia Damaris Müller and Ute Hempel, Institute of Physiological Chemistry, Medical Faculty, Technische Universität Dresden, Dresden D-01307, Germany,

E-mail: sarah.vogel@tu-dresden.de (S.Vogel),

claudia_damaris.mueller@tu-dresden.de (C.D. Müller), ute.hempel@tu-dresden.de (U. Hempel). https://orcid.org/00000002-3640-9815 (C.D. Müller)

Sebastian Köhling, Jan-Niklas Dürig and Jörg Rademann, Institute of Pharmacy, Freie Universität Berlin, Berlin D-14195, Germany, E-mail: sebastian-koehling@gmx.de (S. Köhling), jnduerig@zedat.fu-berlin.de (J.-N. Dürig), joerg.rademann@fu-berlin.de (J. Rademann).https://orcid.org/ 0000-0001-6678-3165 (J. Rademann)

Stephanie Möller and Matthias Schnabelrauch, Biomaterials Department, INNOVENT e.V. Technologieentwicklung Jena, Jena D-07745, Germany, E-mail: SM@innovent-jena.de (S. Möller), ms@innovent-jena.de (M. Schnabelrauch) spectrometry-based (AP-MS) approach to identify novel and particularly intracellular sGAG-interacting proteins in human bone marrow stromal cells (hBMSC). Overall, 477 proteins were found interacting with at least one of four distinct sGAGs. Enrichment analysis for protein localization showed that mainly intracellular and cell-associated interacting proteins were identified. The interaction of SGAG with a2-macroglobulin receptor-associated protein (LRPAP1), exportin-1 (XPO1), and serine protease HTRA1 (HTRA1) was confirmed in reverse assays. Consecutive pathway and cluster analysis led to the identification of biological processes, namely processes involving binding and processing of nucleic acids, LRP1-dependent endocytosis, and exosome formation. Respecting the preferentially intracellular localization of sGAG in vesicle-like structures, also the interaction data indicate sGAG-specific modulation of vesicle-based transport processes. By identifying many sGAG-specific interacting proteins, our data provide a resource for upcoming studies aimed at molecular mechanisms and understanding of sGAG cellular effects.

Keywords: GAG-biotin; hBMSC; LC-MS/MS; pull-down approach; SaOS2/osteoblast cell line; sulfated glycosaminoglycan derivatives.

\section{Introduction}

Glycosaminoglycans (GAGs) are multifunctional polysaccharides of the extracellular matrix (ECM) responsible for ECM hydration and binding of cations and proteins due to their negative charge. GAGs consist of repeating disaccharide units. Two main groups of native GAGs can be distinguished: non-sulfated GAGs, for example, hyaluronan (HA), and sulfated GAGs (sGAGs) like heparin (HE) (Gandhi and Mancera 2008; Salbach et al. 2012). In 2004, Nagahata et al. prepared synthetically sulfated polymeric hyaluronan derivatives (sHA) for the first time, and described the pro-osteogenic effect of the substances (2004). Subsequently, the synthesis and application of defined sulfated hyaluronan-oligosaccharides were 
established (Köhling et al. 2019, 2016a, 2016b). Further investigations have then focused on the potential of artificial sGAGs to modulate regenerative processes in bone (Gronbach et al. 2020; Krieghoff et al. 2019; Scharnweber et al. 2015; Schmidt et al. 2018). Several studies show that both dissolved sHA derivatives and sHA as a component of collagen-based artificial ECM induced tissue non-specific alkaline phosphatase (TNAP, early osteoblast marker) and mineralization (late osteoblast marker) in human bone marrow stromal cells (hBMSC) and osteoblast-precursor cells (Büttner et al. 2013; Hempel et al. 2012, 2014b; Salbach-Hirsch et al. 2014). Applying in vitro- and in silicoanalyses, extracellular sGAG-interaction partners have been identified (Kliemt et al. 2013; Schmidt et al. 2016). It was seen that sHA derivatives strongly affected the assembly, organization and composition of osteoblast-ECM, e.g., due to interaction with fibronectin (FN), sclerostin (SOST), matrix metalloproteinases (MMPs) and their inhibitors (TIMPs) (Rother et al. 2016; Ruiz-Gómez et al. 2019; Salbach-Hirsch et al. 2015; Schmidt et al. 2016; Vogel et al. 2016).

Several investigations suggest that, besides their extracellular actions, also intracellular mechanisms of sGAG-derivatives seem possible. So far, effects on gene expression and the abrogation of transcription factor p65 (RELA) activation were reported (Hempel et al. 2014a). Likewise, some studies show an intracellular accumulation of fluorescence-labeled sGAGs for diverse cell types, such as rat and murine osteocytes, human macrophages, as well as, murine and human bone marrow stromal cells (Jouy et al. 2017; Salbach-Hirsch et al. 2014; Tsourdi et al. 2014; Vogel et al. 2016). However, the underlying mechanisms and cellular functions triggered by internalized sGAG-derivatives are still not well understood. The identification of the intracellular SGAG-interacting proteins could help to unravel these functions.

An exploratory approach to identify such interacting proteins is affinity purification coupled to mass spectrometry (AP-MS). Thereby, interacting proteins (prey) are enriched utilizing ligands of interest bound to a solid support (bait). The enriched proteins are then identified and quantified through quantitative mass spectrometry (MS) (Dunham et al. 2012). Most often, the bait is a protein of interest or a specific antibody. A difficulty in enriching GAG-interacting proteins is the often low affinity resulting in the loss of these proteins applying standard conditions like washing with 300-500 $\mathrm{mM} \mathrm{NaCl}$ (Esko et al. 2015). Glycan-specific antibodies typically have a dissociation constant $\left(K_{D}\right)$ in the range from $10^{-6}$ to $10^{-9} \mathrm{M}$, while the $K_{D}$ for the biotin-avidin-interaction is about $10^{-15} \mathrm{M}$ (Green 1975; Haji-Ghassemi et al. 2014; Purohit et al. 2018). Thus, to reduce a loss of interacting proteins by dissociation from the antibody and use baits for which no specific antibody is available, in situ-biotinylation can be applied (Blumert et al. 2013). By using biotinylated-sGAGs as bait, at least the interacting proteins with the highest affinity can be expected.

This study aimed to identify cell-associated sGAGinteracting proteins and elucidate potential involved cellular processes contributing to the plethora of sGAG effects in vitro. Low- and high-sulfated polymeric HA derivatives, a trideca-sulfated HA-hexasaccharide and, for comparison, native HE were utilized as bait in an AP-MS approach from hBMSC lysates. The identified interactors and associated processes provide a suitable resource for further mechanistic investigations of cell-associated sGAG-effects.

\section{Results}

\section{Sulfated hyaluronans are internalized by hBMSC}

In the first step, the internalization of the four sGAGs low-sulfated polymeric hyaluronan (sHA1), high-sulfated polymeric hyaluronan (sHA3), trideca-sulfo- hyaluronanhexasaccharide (13sHA6-TAMRA), and heparin (HE) by human bone marrow stromal cells (hBMSC) was confirmed by fluorescence microscopy. The hBMSC were treated with fluorescence-labeled sGAG-derivates for $24 \mathrm{~h}$ and counterstained with calcein and DAPI to visualize the complete cell body and nucleus (Figure 1A), or counterstained with phalloidin and DAPI to visualize the actin-cytoskeleton and nucleus (Figure 1B), respectively. All probed sGAGs were internalized by hBMSC and accumulated mainly in vesicle-like structures apart from a minor portion that showed a more diffuse distribution across the inner cell body (Figure 1, red fluorescence).

\section{GAGs interact with multiple intracellular proteins}

To identify cell-associated proteins that interact with sGAGs, biotinylated sGAGs or pure biotin as a negative control bound to NeutrAvidin-coated magnetic particles were used to enrich sGAG-interacting proteins from lysates of hBMSC with subsequent identification and quantification by LC-MS/MS. The composition of the lysates was proved regarding the cellular distribution of input proteins through identification by LC-MS/MS. Subsequently, the annotations for cellular localization were obtained from the GO database (The Gene Ontology Consortium 2019). The lysates contained proteins from all major cellular compartments, and no compartment was 
A

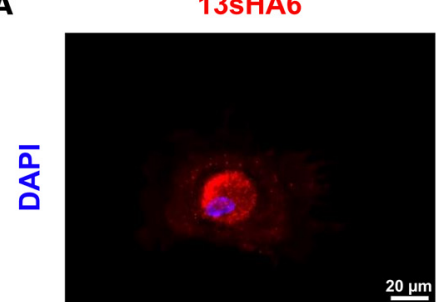

$20 \mu \mathrm{m}$

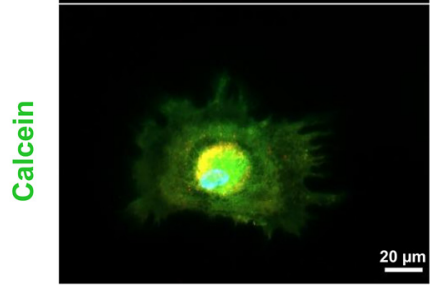

$20 \mu \mathrm{m}$

B

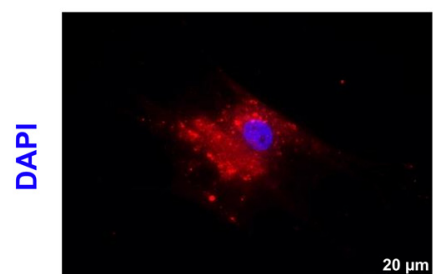

$20 \mu \mathrm{m}$

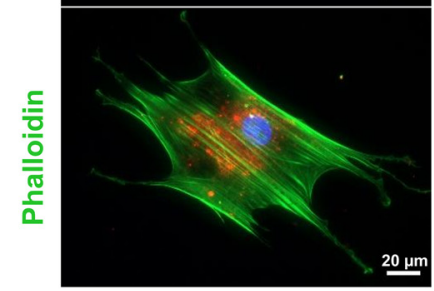

sHA3

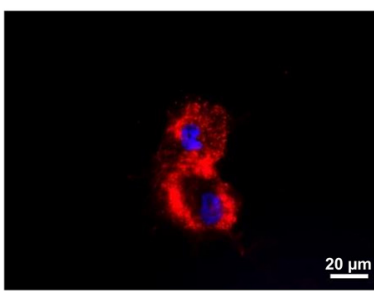

$20 \mu \mathrm{m}$

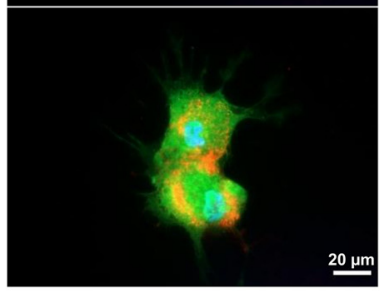

sHA3

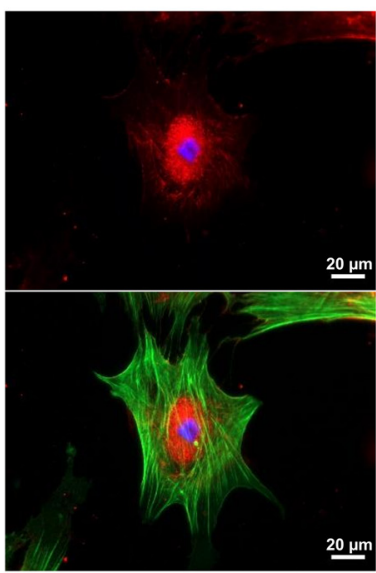

sHA1

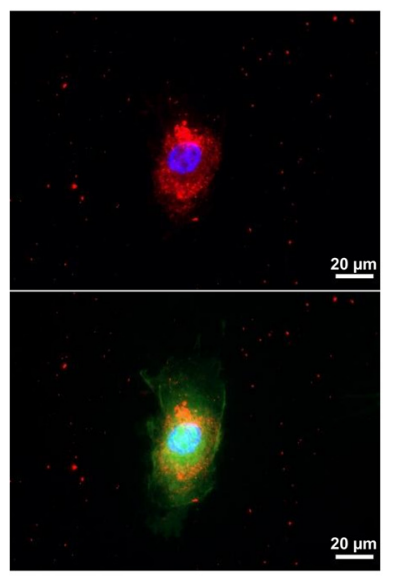

sHA1

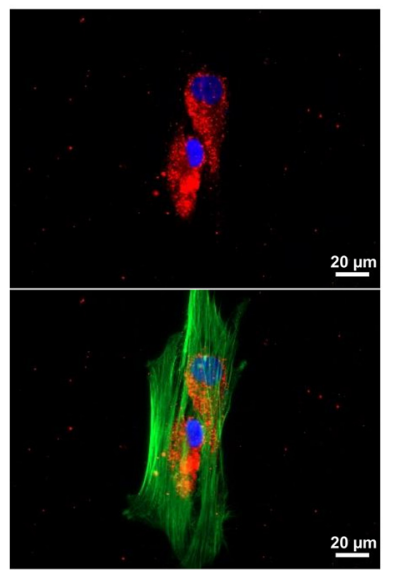

HE

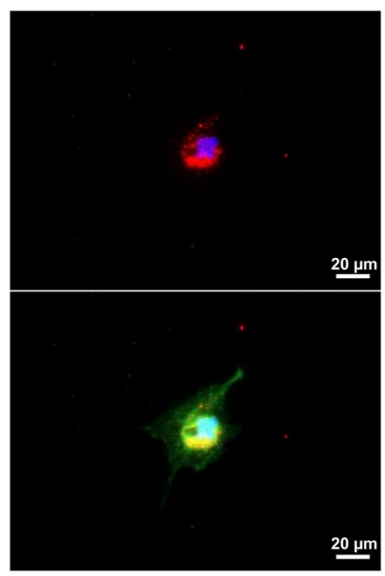

HE

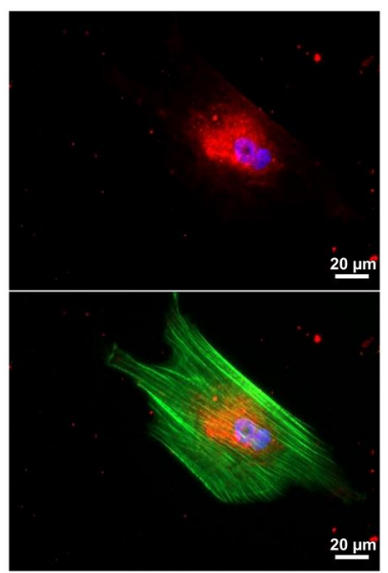

Figure 1: Cellular localization of fluorescence-labeled sGAG-derivates.

The hBMSC were cultured onto glass coverslips and incubated $2 \mathrm{~h}$ after seeding with TAMRA-labeled 13sHA6, Atto565-sHA3, Atto565-sHA1, or Atto565-HE $(200 \mu \mathrm{g} / \mathrm{ml}$ each, red channel). Twenty- four hours after seeding, the cells were counterstained (A) with Calcein-AM (green) for the complete cell body and DAPI for the nuclei (blue) or (B) fixed, permeabilized and counterstained with Alexa488-phalloidin for the actincytoskeleton (green) and DAPI (blue). The scale bar represents $20 \mu \mathrm{m}$.

underrepresented as indicated by all enrichment values being $>1$ (Supplementary Figure 1).

Affinity purification of proteins interacting with 13sHA6-biotin ( $M W=3 \mathrm{kDa}$ ) led to the identification of 216 significantly enriched $(\mathrm{p} \leq 0.01)$ proteins compared to the biotin control (Figure 2A). For the higher molecular weight sGAGs sHA3 (average $\mathrm{MW}=53.7 \mathrm{kDa}$ ) and sHA1 (average $M W=27.3 \mathrm{kDa}$ ), 64 and 70 proteins were concentrated, respectively (Figure $2 \mathrm{~B}$ and $\mathrm{C}$ ). For these sGAGs, ubiquitinassociated protein 2-like (UBAP2L) and 2,4-dienoyl-CoA reductase (DECR1) were the proteins with the highest abundance increase. DECR1 was most enriched for 13sHA6-biotin likewise. The lowest number of proteins, 16, was enriched using generic $\mathrm{HE}$ (average $\mathrm{MW}=15.0 \mathrm{kDa}$ ) (Figure 2D).
In addition to the significantly enriched proteins, multiple proteins were exclusively found in the sGAG samples while not identified in the biotin control. Proteins quantified in at least four of five sGAG samples but utterly absent in the respective controls were rated as pulldown (PD)-exclusive sGAG-interacting proteins. These PD-exclusive proteins added another 179 13sHA6 interactors, 62 sHA3 interactors, 55 sHA1 interactors, and 27 HE-interacting proteins (Figure 2E). Thus, in total 395 potential 13sHA6 interacting proteins were identified, whereas the number for SHA3 and sHA1 was about three times lower. For HE, a limited number of 43 interacting proteins was found. A complete list of interactors is provided in Supplementary Table 1. 
A

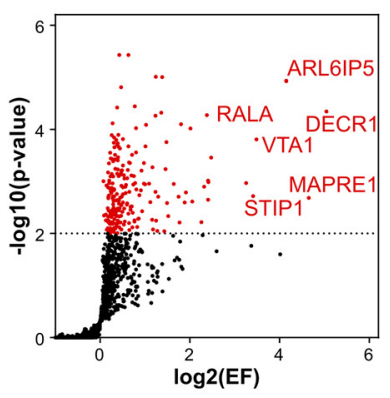

B

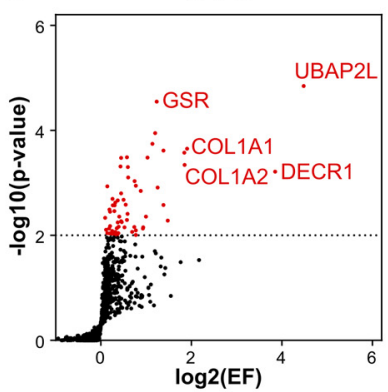

C

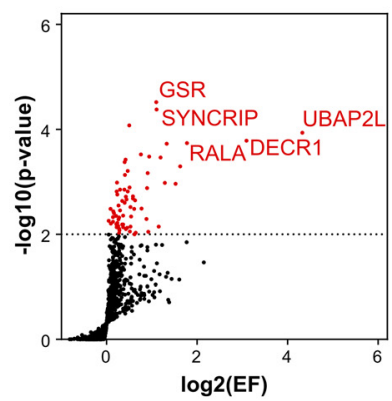

D

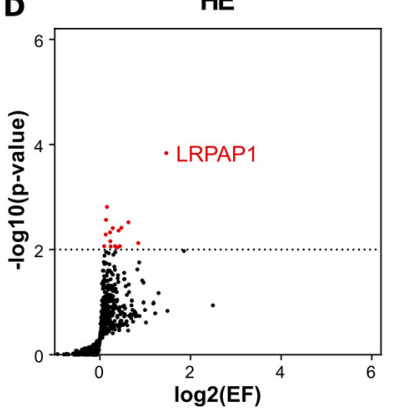

$\mathbf{E}$

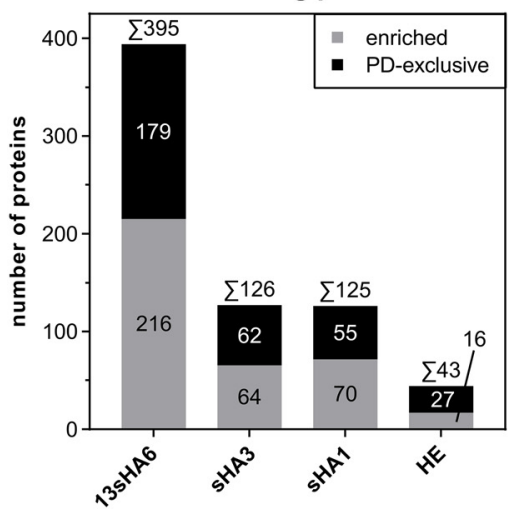

$\mathbf{F}$

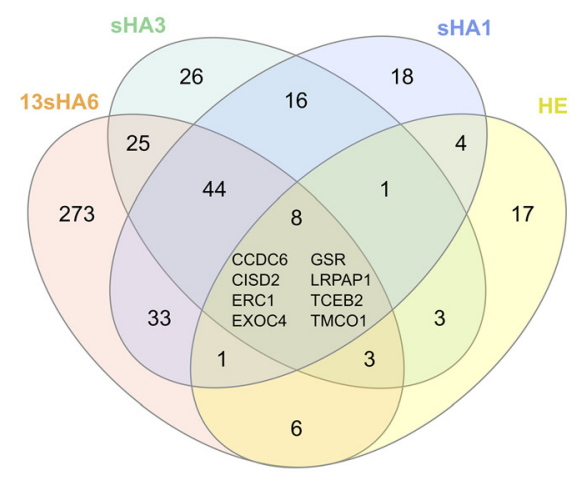

G

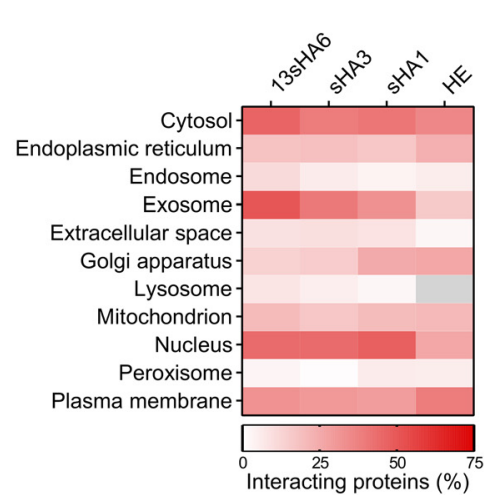

Figure 2: Identification of potential GAG-interactors.

GAG-interacting proteins were enriched with biotinylated 13sHA6 (A), sHA3 (B), sHA1 (C), and HE (D). The respective enrichment-factors were calculated relative to the biotin control PD. Significantly enriched proteins were determined by one-sided, unpaired $t$-tests $(n=5)$. Shown are the negative $\log 10 p$-values in dependency of the log2 enrichment factors. The threshold for significant regulation was $p \leq 0.01$ (dotted line). (E) Number of proteins interacting with the respective SGAG, including significantly enriched proteins (relative to biotin control, grey bar) and proteins exclusive to the PD (black bar). (F) Overlap of proteins interacting with the individual sGAGs used for PD. (G) The cellular localization of interacting proteins is shown as the percentages of interacting proteins for the respective sGAG. Annotations for the cellular localization were obtained from the GO database (The Gene Ontology Consortium 2019). Shown is the relative distribution of identified proteins regarding major cellular components, the extracellular space, and exosomes. CCDC6: Coiled-coil domain-containing protein 6, CISD2: CDGSH iron-sulfur domain-containing protein 2, ERC1: ELKS/Rab6-interacting/CAST family member 1, EXOC4: Exocyst complex component 4, GSR: Glutathione reductase, LRPAP1: $\alpha 2$-macroglobulin receptor-associated protein, TCEB2: Elongin-B, TMCO1: Calcium load-activated calcium channel.

A high number of proteins uniquely interacting with 13 sHA6 coincided with the comparably vast number of interactors identified for this specific GAG (Figure $2 \mathrm{~F}$ ). In contrast, more than half of the sHA3-interacting proteins likewise interacted with SHA1 and vice versa. Interestingly, about $40 \%$ of the HE-interacting were unique to HE. Forty-four proteins bound to all three HA-based sGAGs, but not to HE. The following eight proteins interacted with all four investigated sGAGs: Coiled-coil domain-containing protein 6 (CCDC6), CDGSH iron-sulfur domain-containing protein 2 (CISD2), ELKS/Rab6-interacting/CAST family member 1 (ERC1), exocyst complex component 4 (EXOC4), glutathione reductase (GSR), $\alpha 2$-macroglobulin receptor-associated protein (LRPAP1), elongin-B (TCEB2), and calcium load-activated calcium channel (TMCO1).
To assign the localization of identified sGAG-interacting proteins, the annotations for cellular localization were obtained from the GO database (The Gene Ontology Consortium 2019). Thereby proteins can have multiple annotations for localization and not all entries are validated manually (Gaudet and Dessimoz 2017). The fractions of proteins localized to the major cellular compartments, the extracellular space, and exosomes were calculated for the four investigated sGAGs separately (Figure 2G, Supplementary Table 2). For all sGAGs, interacting proteins from all of these compartments were identified, except for HE, for which no lysosomal proteins were comprised. Only a low number of proteins from the extracellular space, with upmost $9 \%$ of interactors for sHA3, has been identified with our approach. Mutual for all sGAGs was a high fraction of 
cytosolic and plasma membrane-bound interacting proteins. Thereby the membrane-bound fraction was highest for HE with $38.5 \%$. In contrast, sHA1 and sHA3 exhibited a higher tendency to bind to nuclear-localized and exosomally secreted proteins than HE.

Overall, mostly cell-associated proteins were enriched by the PD approach utilized, with only a small share of extracellular proteins. The number of identified interactors was dependent on the GAG-type and, especially, the degree of polymerization.

\section{Selected protein-sGAG interactions are confirmed by reverse PD-assay}

Next, alpha-2-macroglobulin receptor-associated protein (LRPAP1), exportin-1 (XPO1), and serine protease HTRA1 (HTRA1) were selected for confirmation of the proteinsGAG interaction by a reversed PD approach as described. LRPAP1 was found to interact with all sGAG investigated and was previously reported to contain a heparin-binding domain (Furukawa et al. 1990). XPO1 was enriched by 13 sHA 6 only. The protein is mainly localized to the nucleus and was chosen as a prototypic RNA binding protein (Fornerod et al. 1997). HTRA1 was significantly enriched by SHA3 and sHA1. An upregulation of HTRA1 levels and an increased abundance in matrix vesicles was reported for the treatment of hBMSC with sHA (Schmidt et al. 2016, 2018). Additionally, interactions of fibroblast growth factor 2 (FGF2) with sGAGs were previously reported (Köhling et al. 2019; Shipp and Hsieh-Wilson 2007). Thus, FGF2 was included as a positive control for the reversed PD-assay.

In this assay, the proteins were captured from lysates of the osteosarcoma cell line SaOS2 with bead-bound specific antibodies and afterward treated with biotinylated 13sHA6. The amount of protein-bound sGAG was determined by ELISA for its biotin moiety relative to an antibody isotype control. Immobilized XPO1 captured 4.3-times more 13sHA6-biotin than the negative control, and with that, slightly more than the immobilized FGF2 positive control (Figure 3A). LRPAP1 and HTRA1 bound less SGAG than XPO1 and FGF2, but the amount was still significantly higher than for the antibody isotype control samples. Thus, the interactions of 13sHA6 with LRPAP1, XPO1, and HTRA were confirmed by a low-throughput reversed PD-assay.

Additionally, the localization of these proteins within hBMSC was analyzed by immunofluorescence staining of the selected proteins (Figure 3B). FGF2 was mainly localized to the nucleus and, to a minor extent, to the cytoplasm. LRPAP1 accumulated in perinuclear vesicles such as endosomes and Golgi vesicles, which was similar to the internalized sGAGs. XPO1 was found in the nucleus and to a limited amount in perinuclear vesicles. The serine protease HTRA1 accumulated at the outer border of the cells and partially in the extracellular space. Thus, the interaction of proteins from various cellular localizations with 13sHA6 was confirmed, indicating independence of a potential nucleic acid binding function.

\section{A}

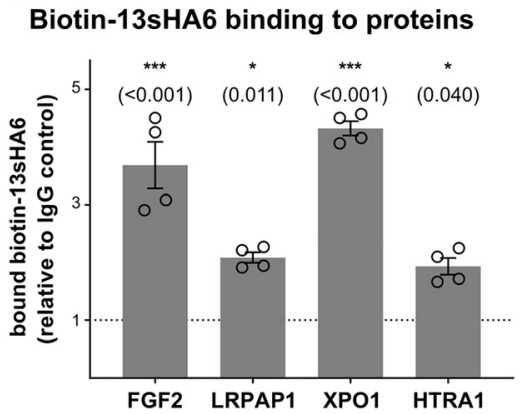

B

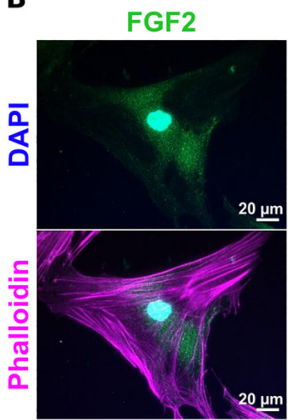

LRPAP1

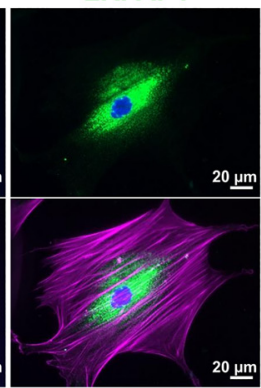

XP01

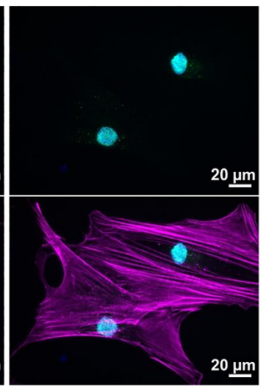

HTRA1

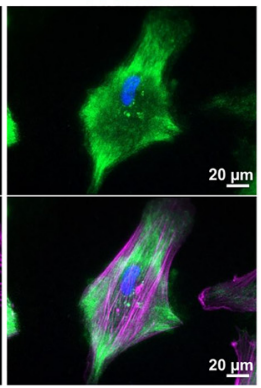

Figure 3: Validation of selected GAG-interacting proteins.

(A) Potential GAG-interacting proteins were captured from lysates of SaOS2 with specific antibodies and subsequently incubated with 13sHA6-biotin. The amount of bound 13sHA6-biotin was determined by ELISA specific for the coupled biotin-moiety relative to the antibody isotype control (IgG). Significance was determined by one-way ANOVA with follow-up Dunnett's multiple comparisons test ( $* \star \star ~=p \leq 0.001$, $\left.\star \star=p \leq 0.01,{ }^{*}=p \leq 0.05\right)$. Data are shown as mean \pm SEM $(n=4)$. (B) The localization of these proteins in hBMSC was visualized by immunofluorescence staining. hBMSC were cultured on glass coverslips for $24 \mathrm{~h}$ and incubated with specific antibodies against FGF2, LRPAP1, XP01, and HTRA1 and secondary Atto488-anti-IgG antibodies (green). Alexa647-phalloidin (pink) and DAPI (blue) were used to stain the F-actin network and nuclei, respectively. The scale bar represents $20 \mu \mathrm{m}$. 


\section{Most interacting proteins participate in cell- cell adhesion and have protein binding properties}

To get insights into how the observed sGAG-protein interactions might contribute to the previously observed effects of sGAG-treatment, like altered gene expression patterns and osteogenic differentiation, the biological processes in which the interactors participate were analyzed. Therefore, the complete lists of interacting proteins were subjected to enrichment analysis against the GO database for molecular functions and biological processes (Supplementary Tables 3 and 4). Mutual for all three HA-based sGAGs was the significant enrichment of proteins associated with cell-cell adhesion (Figure 4A). For sHA1, $12.3 \%$ of interactors participate in cell-cell adhesion. This was the highest share of proteins for one sGAG, although the absolute number was larger for 13sHA6 (42 proteins). The enrichment analysis for molecular functions backed the observation of cell-cell adhesion being the top enriched biological process. The function of cadherin binding involved in cell-cell adhesion was enriched for all HA derivatives, likewise (Figure 4B).

In addition, three biological processes involved in protein maintenance, namely, protein folding, protein transport, and protein stabilization, were enriched (Figure 4A). The significance of enrichment for these processes was based on the 13sHA6-interacting proteins, although SHA3 and sHA1 interactors were associated with these processes, likewise. HE-interactors were associated with two of these processes, namely protein folding and protein transport. Most of the identified sGAG-interacting proteins exhibited a protein-binding function (Figure 4B), which applied for $69 \%$ of 13 sHA6 interactors in the lowest and $75 \%$ of sHA1 interactors in the highest proportion. Since unfolded protein binding and protein homodimerization activity were enriched for 13sHA6-interacting proteins, further significant segregation of protein binding processes was evident. Besides, the function of binding to poly(A) RNA was prevalent among sHA-interacting proteins.

\section{sGAGs interact with complexes of multiple proteins participating in distinct biological processes}

Because of the high fraction of the identified interacting proteins for all investigated sGAGs, the candidates were further analyzed concerning potential clusters of proteins
Biological processes

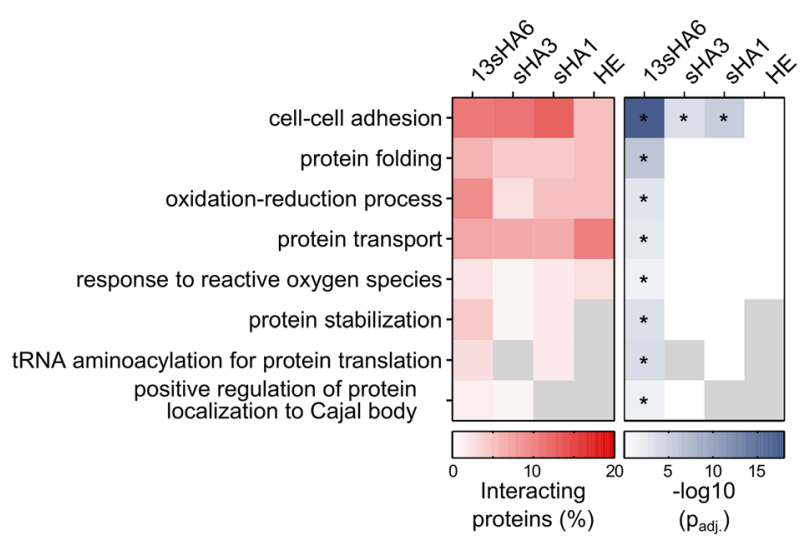

B

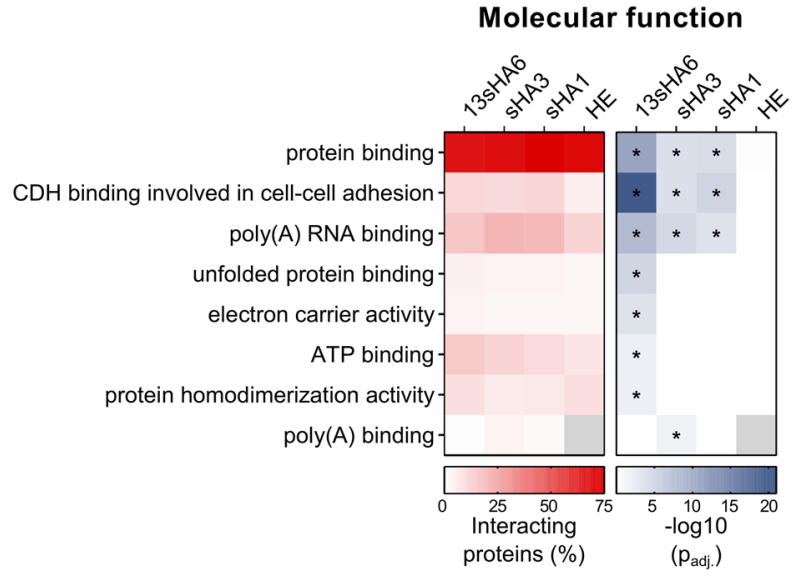

Figure 4: Functional enrichment analysis for sGAG-interacting proteins.

(A) Biological processes and (B) molecular functions associated with identified sGAG-interacting proteins. Depicted are the percentages of interacting proteins annotated for the respective term (left panel) and the Bonferroni adjusted $p$-values $\left(\mathrm{p}_{\mathrm{adj}}\right)$ for enrichment (right panel). Enrichment analysis was conducted using the DAVID bioinformatics resources against the gene ontology database. All molecular functions and biological processes significantly enriched for at least one GAG ( $\left.p_{\text {adj }} \leq 0.05\right)$ are shown. * indicate $p_{a d j} \leq 0.05$, and grey boxes indicate missing values.

interacting with each other. Therefore protein-protein interactions of the identified sGAG-interacting proteins were derived from string database filtering for at least high confidence (Szklarczyk et al. 2019). The obtained clusters of interacting proteins were separately subjected to pathway enrichment analysis.

Clusters of interacting proteins were identified for all four analyzed sGAGs (Figure 5A-D, Supplementary Figure 2). In part, multiple clusters connected via single proteins were observed. Due to the higher number of interactors, most clusters were found for 13sHA6 (Figure 5A, Supplementary Figure 2). All of them contained proteins identified as interactors through significant or exclusive 
enrichment in the PD. The enrichment analysis of the distinct clusters resulted in more detailed processes than the global study. For example, chaperone-mediated protein folding and the response to unfolded proteins were enriched for 13sHA6 interactors rather than the more general protein folding process. Furthermore, eight 13sHA6-interacting proteins are involved in the regulation of gene expression, and seven participate in translation, respectively (Figure 5A).

The processes associated with clusters of sHA3 interactors mainly included cellular organization features (Figure 5B), encompassing the cellular component organization, vesicle-mediated transport, and signal recognition particle (SRP)-dependent cotranslational protein targeting
A

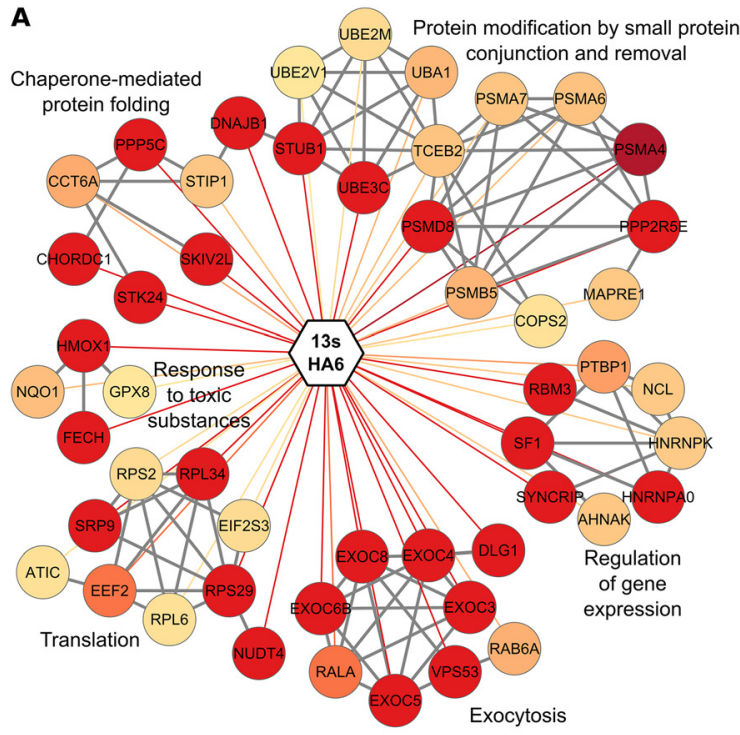

C

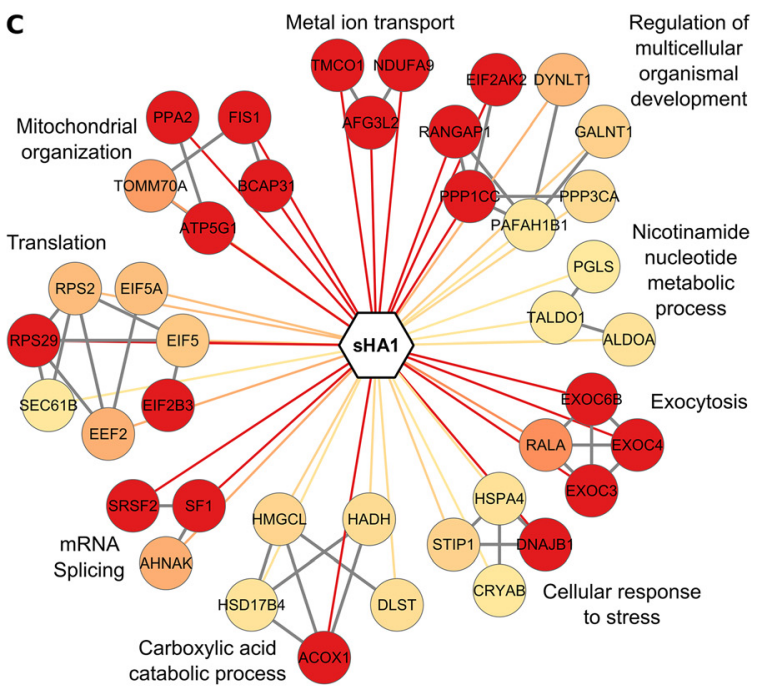

D

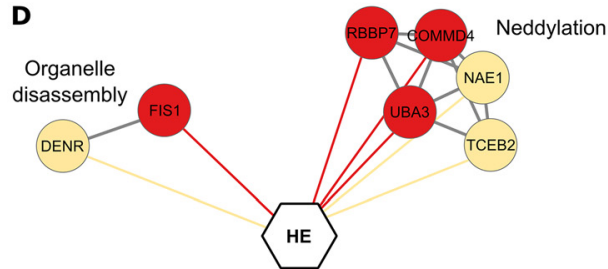

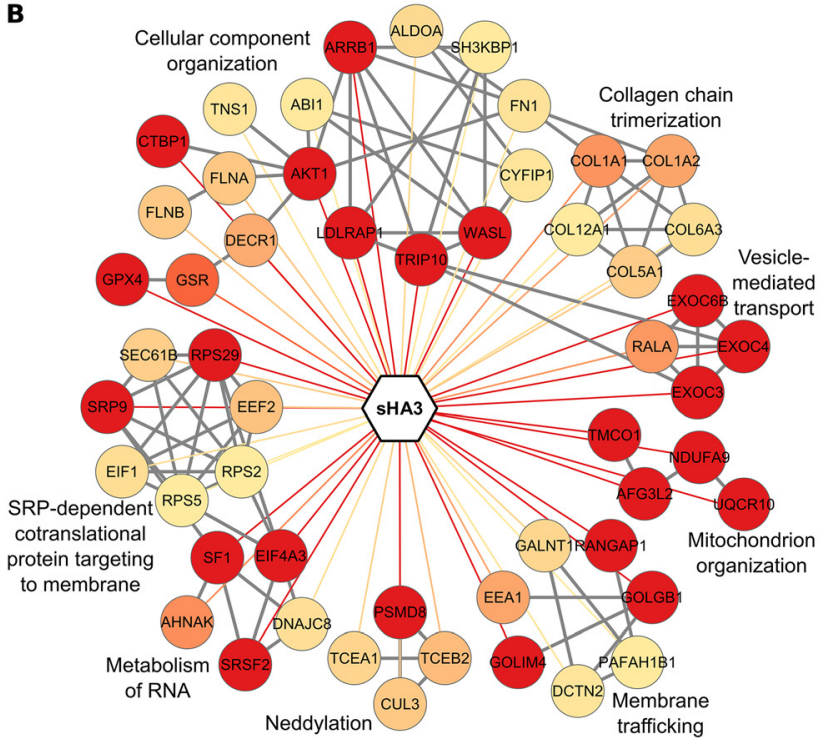

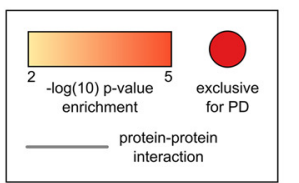

Figure 5: Interactions between GAG-interacting proteins.

Interactions among (A) 13sHA6, (B) sHA3, (C) sHA1, and (F) HE interacting proteins. The described interactions among GAG-interacting proteins were separately extracted from the STRING database for each GAG filtering for at least high confidence. For groups of interacting proteins, enrichment analyses for biological processes were conducted. Shown are clusters of interacting proteins with the most significantly enriched processes within, for which at least half of the respective protein cluster is annotated to this process. For groups of two or three interacting proteins, all proteins had to be associated with the respective term. Proteins without interaction partners and cluster without an associated enriched biological process are excluded. For 13sHA6, only a part of protein clusters is shown. The remaining clusters are given in Supplementary Figure 1. 
to membranes. The two largest protein clusters among sHA1 interactors were enriched for proteins participating in the regulation of multicellular organismal development and translations. In addition, metabolic, e.g., carboxylic acid catabolic processes and transport processes, e.g., exocytosis, were prevalent (Figure $5 \mathrm{C}$ ).

For 13sHA6, the modification of proteins by small protein conjunction and removal was enriched (Figure 5A). This process encompasses ubiquitination but also modification with ubiquitin-like modifiers such as small ubiquitinrelated modifier 2 (SUMO2) or NEDD8 (NEDD8). The process of neddylation, meaning the conjugation of NEDD8 to target proteins, was found enriched for sHA3 (Figure 5B) and was one of only two processes assigned to clusters of HE-interacting proteins (Figure 5D). Furthermore, UBAP2L, which is also a ubiquitin-like modifier, was the most enriched protein in the PD experiments with sHA3 and sHA1.

Taken together, protein clusters participating in distinct biological processes were detected for sGAGs. Thereby the clusters and associated processes were largely specific for individual HA-based sGAGs. The sGAG-specificity might facilitate the targeted use to modulate distinct processes.

\section{Discussion}

The application of artificial, HA-based sGAGs is a promising approach to support the regeneration processes of skin and bone (Salbach et al. 2012). The sGAGs are an integral component of the ECM, and thus most described effects of sGAGs are based on extracellular mechanisms, such as binding to the extracellular proteins FN, SOST, MMPs, and TIMPs (Rother et al. 2016; Ruiz-Gómez et al.
2019; Salbach-Hirsch et al. 2015; Schmidt et al. 2016; Vogel et al. 2016). However, the possibility that some sGAGs are accumulated intracellularly was shown for murine and human BMSC before (Jouy et al. 2015; Vogel et al. 2016). Internalization was confirmed for the sGAGs investigated in this study using fluorescence-labeled derivatives. Despite these findings, the intracellular sGAG effects are scarcely investigated, albeit they likely contribute to the observed effects of sGAG administration.

Utilizing an AP-MS approach, we identified 477 sGAG-protein interactions with artificial, HA-based sGAGs or HE. Recently, a collection of 827 proteins interacting with any of the naturally occurring GAG was published (Vallet et al. 2021). The interactions collected therein were mainly based on targeted assays. To our knowledge, the only global approach was conducted by Gesslbauer et al. (2016). They focused on the interaction of plasma proteins with HE, heparan sulfate (HS), and dermatan sulfate (DS). By comparing the sGAG-interacting proteins identified in this study with the previously known interactors, 92 of the proteins were previously described as GAG-interacting, while 385 are novel interactors. A selection of previously described GAG-interacting proteins is shown in Table 1; a complete list is provided in Supplementary Table 5. Most of the 92 known interactors are localized to the extracellular region. This was expected since naturally occurring GAG are mainly present in the ECM and on the cell surface (Kowitsch et al. 2018). For example, FN, which was here found to interact with sHA3, is known to interact with HE, DS, HS, and sHA1 (Gesslbauer et al. 2016; Sachchidanand et al. 2002; Vogel et al. 2016).

Proteins with binding function to poly(A) RNA were significantly enriched for all HA-based sGAGs investigated

Table 1: Selected sGAG-interacting proteins identified in this study with previously described interactors.

\begin{tabular}{|c|c|c|c|c|c|c|c|}
\hline \multirow[t]{2}{*}{ Protein } & \multirow{2}{*}{$\begin{array}{l}\text { Gene } \\
\text { name }\end{array}$} & \multirow{2}{*}{$\begin{array}{l}\text { SwissProt- } \\
\text { ID }\end{array}$} & \multicolumn{2}{|c|}{ Interacting GAG } & \multirow[t]{2}{*}{ Localization } & \multirow[t]{2}{*}{ Method } & \multirow[t]{2}{*}{ Reference } \\
\hline & & & Study & Ref. & & & \\
\hline \multirow[t]{3}{*}{ Fibronectin } & FN1 & P02751 & sHA3 & sHA1;HE & $\begin{array}{l}E S, E X, E R, \\
P M\end{array}$ & $\begin{array}{l}\text { Colocalization, } \\
\text { Fiber Stretch }\end{array}$ & (Vogel et al. 2016) \\
\hline & & & & $\begin{array}{l}\text { HE, DS, } \\
\text { HS }\end{array}$ & & AP-MS & $\begin{array}{l}\text { (Gesslbauer et al. } \\
\text { 2016) }\end{array}$ \\
\hline & & & & $\mathrm{HE}$ & & NMR, ITC & $\begin{array}{l}\text { (Sachchidanand et al. } \\
\text { 2002) }\end{array}$ \\
\hline Prenylcysteine oxidase 1 & PCYOX1 & Q9UHG3 & $13 \mathrm{sHA} 6$ & $\mathrm{HE}$ & LS, EX & AP-MS & $\begin{array}{l}\text { Gesslbauer et al. } \\
\text { (2016) }\end{array}$ \\
\hline $\begin{array}{l}\text { PRKC apoptosis WT1 regulator } \\
\text { protein }\end{array}$ & PAWR & Q961Z0 & $\mathrm{HE}$ & $\mathrm{HE}$ & NC, PM & AP-MS & $\begin{array}{l}\text { Gesslbauer et al. } \\
(2016)\end{array}$ \\
\hline (Pro-) low-density lipoprotein & LRP1 & Q07954 & $13 \mathrm{sHA} 6$ & sHA & PM, EN, LS & SPR & (Rother et al. 2016) \\
\hline receptor-related protein 1 & & & & HS & & Colocalization & (Kanekiyo et al. 2011) \\
\hline
\end{tabular}

A complete list is provided in Supplementary Table 5, DS, Dermatan sulfate; EN, Endosome; ER, endoplasmatic reticulum; ES, Extracellular space; EX, Exosome; GA, Golgi apparatus; HS, Heparan sulfate; LS. Lysosome; NC. Nucleus; PM, Plasma membrane. 
in this study. This came with 13sHA6, sHA3, and sHA1 exhibiting clusters of interacting proteins directly involved in nucleic acid centered processes. Among 13sHA6interacting proteins, clusters associated with translation and the regulation of gene expression were identified. Translation associated proteins formed a cluster among sHA3-interactors likewise, as did proteins involved in mRNA splicing, while RNA metabolism and SRP-dependent cotranslational protein targeting to membranes were enriched among clusters of sHA3-interactors. The interaction of GAG with proteins is mainly based on ionic interactions, as excellently reviewed by Gandhi and Mancera (2008). The binding involves negative charges introduced by sulfation and basic amino acids, mainly lysine and arginine. Thereby binding with arginine is tighter (Hileman et al. 1998). This extends to nucleic acid-protein binding with the addition that for nucleic acids the ion atmosphere can contribute to binding (Lipfert et al. 2014; Yan et al. 2006). Therefore, it appears likely that sGAGs interfere with these nucleic acid centered processes through sequestration of involved proteins, once they are in the cytosol or nucleus.

The endocytic receptor LRP1 was found to interact with 13sHA6-biotin in this study, while interaction with HS was previously reported by Kanekiyo et al. (2011). LRP1 is a surface receptor responsible for endocytosis and lysosomal targeting of proteins and lipoproteins (Lillis et al. 2008). Lysine and arginine residues within multiple ligands, such as apolipoprotein E (ApoE) and plasminogen activator inhibitor 1 (SERPINE1), are essential for binding to LRP1 (Lalazar et al. 1988; Morrow et al. 2000; Rodenburg et al. 1998). As mentioned, lysines and arginines are a requirement for nucleic acid and sGAG-binding based on the negative charges (Gandhi and Mancera 2008; Yan et al. 2006). Thus, a direct binding of 13 sHA6 to the negatively charged ligand binding domains of LRP1 is unlikely (Dolmer et al. 2013). Rather an LRP1 containing proteincomplex was enriched, e.g., SERPINE1 was enriched by 13sHA6-biotin likewise. A prominent LRP1-interacting protein is LRPAP1 (Cuitino et al. 2005; Huttlin et al. 2017; Williams et al. 1992). LRP1 has two binding sites for LRPAP1. Dependent on receptor binding sites, LRPAP1 can act as an activator or inhibitor of endocytosis of proteins binding to these sites (Williams et al. 1992). Interestingly, while LRP1 was only enriched by 13sHA6-PD, all sGAGs investigated in this study were found to interact with LRPAP1. Overall, the interaction data indicate that protein recycling from the ECM through LRP1 is rather inhibited than stimulated by sGAGs in general. This also provides a potential mechanism for the enrichment of several ECM proteins, e.g., FN, after treatment with sGAGs (Schmidt et al. 2016, 2018; Vogel et al. 2016). For the increase of extracellular levels of tissue inhibitor of metalloproteinase3 (TIMP3), this mechanism was already proposed, based on the blockage of LRP1-TIMP3 interaction by SHA and chondroitin sulfate (CS) (Rother et al. 2016).

Besides internalization processes, sGAGs are likely involved in exocytosis and the generation of multivesicular bodies and exosomes. Protein clusters involved in exocytosis, especially vesicle-mediated transport, were enriched by all three sHA applied (Figure 5A-C). A cluster involved in multivesicular body assembly was enriched by 13 sHA6 likewise (Supplementary Figure 2). Besides, a high fraction of proteins interacting with these sGAGs is localized in exosomes. Exosomes are extracellular vesicles secreted through the fusion of multivesicular bodies with the plasma membrane (Bobrie et al. 2011; Colombo et al. 2013). The exosomes provide an additional layer for communication between osteoblasts and osteoclasts (Deng et al. 2015). The potential involvement of sGAGs in vesiclemediated endocytosis and exocytosis is further supported by the vesicle-like localization of intracellular sGAGs observed in this study. Recently, the use of defined exosomes in cartilage therapy and bone complications was proposed (Pourakbari et al. 2019). In that line, the stimulation of matrix vesicle secretion and alteration of their composition upon treatment of hBMSC with SHA1 was described by Schmidt et al. (2016). However, the extraction and specified loading of exosomes prove difficult. The data presented in this study indicate that sHA may modulate the composition and release of exosomes from hBMSC and that this modulation may partially mediate their pro-osteogenic effect and ECM-remodeling.

Taken together, 477 sGAG-interacting, intracellular and cell-associated proteins were identified in this study. Thereby a dependency on the degree of GAG polymerization and sulfation on sGAG-protein interactions was shown, resulting in interaction partners specific to distinct sGAGs. Pathway and cluster analysis of interacting proteins led to the identification of biological processes, namely processes involving binding and processing of nucleic acids, LRP1-dependent endocytosis, and exosome formation, likely affected by sGAG administration. Especially, in combination with the observed vesicle-like localization of internalized sGAGs, a modulation of vesicle-mediated transport processes is indicated. Still, the exact effects of the identified sGAG-protein interactions on these processes remain to be elucidated in targeted, low-throughput assays. Thus, the interaction data presented here constitutes a valuable resource for understanding and researching sGAG-effects in healing and thus therapy. 


\section{Materials and methods}

All chemicals were purchased from Sigma (Taufkirchen, Germany) unless otherwise noted.

\section{Sulfated glycosaminoglycan derivatives (sGAGs)}

Polymeric sulfated hyaluronans (sHA1 and sHA3) were synthesized and characterized as previously described (Hintze et al. 2009; Kunze et al. 2010). Detailed information on the synthesis are given in the supplementary methods. Biotinylated trideca-sulfated hyaluronan-hexasaccharide (13sHA6-biotin) was synthesized from trideca-sulfo-hyaluronan-hexasaccharide azide 13s-HA6-azide and N-Propargyl-8-((+)-biotinyl-amino)-3,6-dioxa-octanamide.

Detailed information on the synthesis and NMR and MS based controls are given in the supplementary methods.

The properties and structures of all applied functionalized sGAG are given in Table 2 and Supplementary Figure 3.

\section{Cell culture}

Human bone marrow stromal cells (hBMSC) were isolated from bone marrow aspirates that were collected from healthy donors (Caucasian males, average age $39.5 \mathrm{y}$ ) at the Bone Marrow Transplantation Centre of the University Hospital Dresden. The study was approved by the local ethics commission (ethic vote No. EK466112016), and the donors gave their full consent. hBMSC were isolated, according to Oswald et al. (2004). For the experiments, hBMSC were used in passage 4-6. hBMSC from different donors were not pooled and referred to as independent biological replicates.

For the experiments, hBMSC were cultured in Dulbecco's minimum essential medium (DMEM) (low glucose, Biochrom, Berlin, Germany) supplemented with 10\% heat-inactivated fetal calf serum (HI-FCS, BioWest via Th. Geyer, Hamburg, Germany) in tissue culture polystyrene flasks $\left(75 \mathrm{~cm}^{2}\right.$, TCPS; Greiner bio-one, Frickenhausen, Germany) until confluence after about 3-5 weeks.

SaOS2 cells (osteosarcoma cell line) purchased from ATCC (via LCG standards, Wesel, Germany) were cultured in McCoys-5A medium supplemented with $15 \%$ HI-FCS in $75 \mathrm{~cm}^{2}$-TCPS flasks until confluence for about 1 week.

Confluent cell layers were rinsed twice with PBS and lysed with $500 \mu \mathrm{l}$ of RIPA-buffer ( $50 \mathrm{mM}$ Tris- $\mathrm{HCl} \mathrm{pH} \mathrm{7.8,} 150 \mathrm{mM} \mathrm{NaCl}, 1 \% \mathrm{NP}-40$, $0.25 \%$ sodium deoxycholate, $1 \mathrm{mM}$ EDTA) supplemented with $1 \%$ of aprotinin, $1 \mathrm{mM}$ PMSF and $100 \mu \mathrm{M}$ sodium vanadate per flask for 10 min on ice. Afterwards, cell lysates were collected and centrifuged at $13.000 \mathrm{~g}$ for $30 \mathrm{~min}$ at $4{ }^{\circ} \mathrm{C}$. The protein content of the lysates was determined with RotiQuant ${ }^{\circledR}$ protein assay (Roth, Karlsruhe, Germany) and with bovine serum albumin (BSA) as a standard.

\section{Fluorescence staining}

hBMSC were cultured for $24 \mathrm{~h}$ on glass coverslips. To visualize the complete cell body, samples were incubated with calcein-AM $(0.5 \mu \mathrm{L}$ of a $4 \mathrm{mM}$ stock solution/mL of PBS) for $30 \mathrm{~min}$ at $37^{\circ} \mathrm{C}$ according to manufacturer's instructions (LIVE/DEATH assay kit, Invitrogen, via ThermoFisher, Dreieich, Germany). The cell-permeable calcein-AM dye is converted to green-fluorescent calcein by ubiquitous cellular esterases. For immunofluorescence staining, hBMSC were fixed with 4\% paraformaldehyde for $10 \mathrm{~min}$ and permeabilized with $0.1 \%$ Triton $\mathrm{X}-100$ in PBS for 20 min followed by blocking with $1 \%$ BSA in $0.05 \%$ Tween-20-containing PBS for $5 \mathrm{~min}$. The following primary antihuman antibodies were used in blocking buffer for $1 \mathrm{~h}$ : XPO1 (\#46249, 1:400, Cell Signaling, Frankfurt, Germany), LRPAP1 (11100-RP02, 1:100, Sino Biological, USA), FGF2 (A0235, 1:25, ABclonal Technology, USA), and HTRA1 (PAC258Hu01, 1:100, CLOUD-CLONE CORP., USA). The secondary antibodies (AlexaFluor488-conjugated goat anti-mouse IgG (A11001, Invitrogen), and AlexaFluor488-conjugated donkey anti-rabbit IgG (A21206, Invitrogen)) were applied together with Alexa647-phalloidin (A12380, 1:250, Invitrogen via ThermoFisher, Schwerte, Germany). To visualize actin cytoskeleton solely, Alexa488-phalloidin (A12379, 1:250, Invitrogen via ThermoFisher, Schwerte, Germany) was applied to fixed, permeabilized and blocked cells instead of calcein-AM. Nuclei were stained with $0.2 \mu \mathrm{g}$ 4',6-diamidino-2-phenylindole (DAPI)/ml. Cells were embedded in Mowiol 4-88 and visualized using a Z1 Imager equipped with a 40× oil-objective (Carl Zeiss, Oberkochen, Germany).

Table 2: Characteristics of sGAG-derivatives.

\begin{tabular}{|c|c|c|c|c|c|}
\hline GAG & Description & Functionalization & $\begin{array}{r}\text { Degree of } \\
\text { sulfation (D.S.) }\end{array}$ & $\begin{array}{r}\text { Marker group } \\
\text { content }(\mu \mathrm{g} / \mathrm{mg})\end{array}$ & $\begin{array}{r}\text { Molecular } \\
\text { weight (kDa) }\end{array}$ \\
\hline \multirow[t]{2}{*}{$13 \mathrm{sHA}^{\mathrm{a}}$} & Trideca-sulfo-hyaluronan-hexasaccharide & Biotin (end-on) ${ }^{\mathrm{a}}$ & 4.3 & - & 2.998 \\
\hline & & TAMRA (end-on) ${ }^{a}$ & & - & 3.039 \\
\hline \multirow[t]{2}{*}{$\mathrm{sHA} 3^{b}$} & Polymeric, high-sulfated HA & Biotin (side-on) ${ }^{b}$ & 3.5 & 0.9 & $53.700^{\mathrm{e}}$ \\
\hline & & Atto 565 (side-on) $^{\mathrm{b}}$ & 3.4 & 1.0 & $32.100^{\mathrm{e}}$ \\
\hline \multirow[t]{2}{*}{$\mathrm{SHA} 1^{\mathrm{b}}$} & Polymeric, low-sulfated HA & Biotin (side-on) ${ }^{b}$ & 1.2 & 0.8 & $27.300^{\mathrm{e}}$ \\
\hline & & Atto565 (side-on) ${ }^{b}$ & 1.4 & 2.0 & $14.600^{\mathrm{e}}$ \\
\hline \multirow[t]{2}{*}{$H E^{c / d}$} & Heparin & Biotin (end-on) ${ }^{d}$ & 3.0 & - & $15.000^{\mathrm{e}}$ \\
\hline & & Atto 565 (side-on) ${ }^{b}$ & & 3.3 & \\
\hline
\end{tabular}

${ }^{a}$ Synthesized and kindly provided from Institute of Pharmacy, Freie Universität Berlin, Germany, ${ }^{b}$ synthesized and kindly provided from Biomaterials Department, INNOVENT e.V., Jena, Germany, ' purchased (H3393, Sigma, Taufkirchen, Germany), ${ }^{d}$ purchased (B9806, Sigma, Taufkirchen, Germany), eaverage molecular weight values as determined by gel permeation chromatography (GPC) equipped with Laser Light Scattering (LLS) detection. 


\section{Pull-down of GAG-interacting proteins}

Same amounts of biotinylated GAGs or biotin $(17.5 \mathrm{nmol})$ were incubated with NeutrAvidin coated magnetic particles (Sera-Mag ${ }^{\mathrm{TM}}$ SpeedBeads ${ }^{\mathrm{TM}}$, GE Healthcare, USA) in pull-down (PD) buffer ( $25 \mathrm{mM}$ Tris/HCl, pH7.4; 75 mM NaCl; 0.5\% NP-40; 0.125\% Na-deoxycholate; $1 \mathrm{mM}$ EDTA) for $1 \mathrm{~h}$ with constant rotation at $4{ }^{\circ} \mathrm{C}$. Bead-bound GAGs were subsequently washed two times with PD-buffer. The hBMSC cell lysates equivalent to $500 \mu \mathrm{g}$ protein were pre-cleared with NeutrAvidin coated magnetic particles in PD buffer for 30 min with constant rotation at $4{ }^{\circ} \mathrm{C}$. The pre-cleared lysates were combined with the beadbound GAGs or bead-bound biotin. Interacting proteins were captured for $90 \mathrm{~min}$ with constant rotation at $4{ }^{\circ} \mathrm{C}$. The beads were washed two times with $1 \mathrm{ml}$ PD buffer and one time with detergent-free lysis buffer. The captured proteins were eluted with $2 \times$ Laemmli buffer under heating $\left(65^{\circ} \mathrm{C}\right)$ and shaking for $5 \mathrm{~min}$.

\section{Protein purification and digestion}

Proteins from cell lysates and pull-down eluates were proteolytically cleaved using a paramagnetic bead approach based on Hughes et al. (2019). In short, sample proteins were precipitated on magnetic carboxylate modified particles (Sigma-Aldrich, USA) by adding acetonitrile to a final concentration greater than $50 \%$ and washed with pure ACN and 70\% ACN. Precipitated proteins were reduced with $50 \mathrm{mM}$ TCEP (Sigma-Aldrich, USA), carbamidomethylated with 100 mM IAA (Merck, Germany), and proteolytically cleaved with trypsin (Promega, USA) applied in a 1:50 trypsin:protein-ratio for $16 \mathrm{~h}$. The peptides containing supernatants were collected and dried to completeness using a vacuum concentrator.

\section{LC-MS/MS analysis}

LC-MS/MS analysis of samples was performed on an UltiMate 3000 RSLCnano system (Dionex, USA), online coupled to a Q Exactive HF mass spectrometer (Thermo Fisher Scientific, USA) by a chip-based electrospray ionization source (TriVersa NanoMate, Advion, USA). Peptides were trapped and desalinated on a C18 pre-column (Acclaim PepMap 100, $75 \mu \mathrm{m} \times 2 \mathrm{~cm}, \mathrm{C18}, 3 \mu \mathrm{m}$ ), and subsequently separated on a C18 analytical column (Acclaim PepMap RSLC, $75 \mu \mathrm{m} \times 25 \mathrm{~cm}$, C18, $2 \mu \mathrm{m}$ ).

For proteome analysis, a bipartite linear 95 min gradient starting from $4 \%$ eluent $\mathrm{B}(0.1 \% \mathrm{FA}$ in $80 \% \mathrm{ACN})$ in eluent $\mathrm{A}(0.1 \% \mathrm{FA}$ in water $)$ to $55 \%$ eluent B via $30 \%$ eluent B after 70 min was used. After each sample, the column was flushed to $99 \%$ eluent B and reconstituted to starting conditions. Mass spectra were acquired in a data-dependent manner. For MS1 scans, the following parameters were set: $m / z$ range $350-1600$, maximum injection time $=150 \mathrm{~ms}$, automated gain control $(\mathrm{AGC})=3 \times 10^{6}, R=60,000$. The top 10 most abundant ions were selected for MS2 acquisition using the following parameters: isolation window of $1.4 \mathrm{~m} / \mathrm{z}$, maximum injection time $150 \mathrm{~ms}, \mathrm{AGC}=2 \times 10^{5}$, normalized collision energy $(\mathrm{NCE})=28, R=15,000, \mathrm{~m} / \mathrm{z}$ range 200-2,000. Fragmented ions were dynamically excluded for $30 \mathrm{~s}$.

\section{LC-MS/MS data analysis}

The LC-MS/MS raw data for proteome and phosphoproteome were examined by MaxQuant (Version 1.6.7.0) (Cox et al. 2014). The database search was performed against the Uniprot Homo sapiens RefSet (09/2019, 74349 entries) and a list of common contaminants provided by MaxQuant (07/2019, 245 entries) (UniProt 2019). Search parameters were set as follows: Maximum missed cleavages $=2$, minimal peptide length $=6$ amino acids, first search peptide tolerance $=20 \mathrm{ppm}$, main search peptide tolerance $=4.5 \mathrm{ppm}$, FTMS MS $/ \mathrm{MS}$ match tolerance $=20 \mathrm{ppm}$. Carbamidomethylation of cysteine was set as a fixed modification, protein $\mathrm{N}$-terminal acetylation, and oxidation of methionine as variable modifications. A minimum of two unique peptides was required for protein quantification. Peptides, proteins, and sites were filtered by a target-decoy approach to a FDR $\leq 0.01$ using a reversed decoy database. Match between runs was enabled with a match time window of $0.7 \mathrm{~min}$ and an alignment time window of $20 \mathrm{~min}$. Label-free quantification (LFQ) was used for relative protein quantification based on an LFQ ratio count $\geq 2$.

Perseus (Version 1.6.10.43) was used for further statistical analysis. First, proteins identified by site, from the reverse database, or as potential contaminants were removed. LFQ-intensities were log2transformed. The dataset was split into two parts, one with proteins not identified in any of the biotin controls and one with proteins identified in at least one control sample. PD-exclusive interacting proteins were then identified by filtering for quantification in at least four of $5 \mathrm{PD}$-experiments with the respective GAG within the list of proteins not identified in any control-PD. For the identification of enriched proteins, missing values were imputed with random values drawn from a normal distribution ( width $=0.3$, downshift $=1.8$ ) for the control-PD only. Significantly altered proteins were then identified by one-sided, paired $t$-tests. To be included, proteins had to be quantified in at least four of 5 PD-experiments. The threshold for significant alteration was set at $p \leq 0.01$.

\section{Functional annotation and enrichment analysis}

Functional annotation and enrichment analysis regarding localization, molecular functions, and biological processes was done utilizing DAVID bioinformatics resources (Huang da et al. 2009). Annotations were based on the gene ontology resource database (GO) (Ashburner et al. 2000; The Gene Ontology Consortium 2019). Only MF and BP with a Benjamini corrected $p$-value $\leq 0.05$ were considered as significantly enriched. Previously reported protein-protein interactions within the groups of identified GAG-interacting proteins were analyzed using STRING (Version 11.0) with the following settings: active interaction sources $=$ textmining \& experiments \& databases; minimum required interaction score $=$ high confidence (0.700). Functional enrichment analysis for clusters of interacting proteins was conducted using the built-in analysis function, selecting biological processes from GO (Szklarczyk et al. 2019).

\section{Reverse pull-down and quantification of biotin moieties}

Magnetic protein A/G beads were washed twice with RIPA buffer and coupled with antibodies specific to potential GAG-interacting proteins. Anti-FGF2 served as a positive control, and normal IgG was used for negative control. The coupling of antibodies was carried out for $1 \mathrm{~h}$ with constant rotation at $4^{\circ} \mathrm{C}$. Afterward, the beads were washed two times with RIPA buffer and used for PD of target proteins from cell lysate for $1 \mathrm{~h}$ with constant rotation at $4^{\circ} \mathrm{C}$. Lysates from the SaOS2 cell line were used for the reverse assay. The beads were washed two times 
with RIPA buffer and one time with PBS. Washed beads were incubated with $2.18 \mathrm{nmol} 13 \mathrm{sHA6}$-biotin for $30 \mathrm{~min}$ with constant rotation at $4{ }^{\circ} \mathrm{C}$ and washed three times with PBS. Captured proteins and 13sHA6-biotin were eluted at low $\mathrm{pH}(0.1 \mathrm{M}$ glycine/ $\mathrm{HCl}, \mathrm{pH} 2)$, and the $\mathrm{pH}$ of eluates was neutralized (1 M Tris/HCl, $\mathrm{pH} 7.5$ ).

For reverse PD experiments, the same antibodies against FGF2, LRPAP1, XPO1 and HTRA1 were used as for immunofluorescence staining above. Rabbit normal IgG (sc-2027, Santa Cruz Biotechnology, USA) was used for unspecific control PD.

The amount of biotin moieties linked to 6psHA in the eluates was determined by the competitive Biotin ELISA Kit (Catalog number MBS706024, MyBioSource, USA). Samples were diluted 1:5 before ELISA. One-way ANOVA with follow-up Dunnett's multiple comparisons test was used to determine the significant capture of 13sHA6biotin by the bead-bound proteins compared to the normal IgG control. The significance threshold was set at $p \leq 0.05$.

Acknowledgments: The authors thank Petra Mitzscherling (TU Dresden) for excellent technical assistance.

Author contributions: All the authors have accepted responsibility for the entire content of this submitted manuscript and approved submission.

Research funding: This study was supported by grants from the Deutsche Forschungsgemeinschaft Transregio 67 (subprojects Z4, B1, Z3, and A8) as well as by a scholarship from the Graduate Academy of TU Dresden (CDM).

Conflict of interest statement: The authors declare no conflicts of interest regarding this article. Data and materials availability: The proteomics data have been deposited to the ProteomeXchange Consortium via the PRIDE partner repository with the dataset identifier PXD023362 (Deutsch et al. 2020).

\section{References}

Ashburner, M., Ball, C.A., Blake, J.A., Botstein, D., Butler, H., Cherry, J.M., Davis, A.P., Dolinski, K., Dwight, S.S., Eppig, J.T., et al. (2000). Gene ontology: tool for the unification of biology. The Gene Ontology Consortium. Nat. Genet. 25: 25-29.

Blumert, C., Kalkhof, S., Brocke-Heidrich, K., Kohajda, T., Von Bergen, M., and Horn, F. (2013). Analysis of the STAT3 interactome using in-situ biotinylation and SILAC. J. Proteomics 94: 370-386.

Bobrie, A., Colombo, M., Raposo, G., and Thery, C. (2011). Exosome secretion: molecular mechanisms and roles in immune responses. Traffic 12: 1659-1668.

Büttner, M., Moller, S., Keller, M., Huster, D., Schiller, J., Schnabelrauch, M., Dieter, P., and Hempel, U. (2013). Over-sulfated chondroitin sulfate derivatives induce osteogenic differentiation of hMSC independent of BMP-2 and TGF-beta1 signalling. J. Cell. Physiol. 228: 330-340.

Colombo, M., Moita, C., Van Niel, G., Kowal, J., Vigneron, J., Benaroch, P., Manel, N., Moita, L.F., Thery, C., and Raposo, G. (2013). Analysis of ESCRT functions in exosome biogenesis, composition and secretion highlights the heterogeneity of extracellular vesicles. J. Cell Sci. 126: 5553-5565.

Cox, J., Hein, M.Y., Luber, C.A., Paron, I., Nagaraj, N., and Mann, M. (2014). Accurate proteome-wide label-free quantification by delayed normalization and maximal peptide ratio extraction, termed MaxLFQ. Mol. Cell. Proteomics 13: 2513-2526.

Cuitino, L., Matute, R., Retamal, C., Bu, G., Inestrosa, N.C., and Marzolo, M.P. (2005). ApoER2 is endocytosed by a clathrinmediated process involving the adaptor protein Dab2 independent of its Rafts' association. Traffic 6: 820-838.

Deng, L., Wang, Y., Peng, Y., Wu, Y., Ding, Y., Jiang, Y., Shen, Z., and Fu, Q. (2015). Osteoblast-derived microvesicles: a novel mechanism for communication between osteoblasts and osteoclasts. Bone 79: 37-42.

Deutsch, E.W., Bandeira, N., Sharma, V., Perez-Riverol, Y., Carver, J.J., Kundu, D.J., Garcia-Seisdedos, D., Jarnuczak, A.F., Hewapathirana, S., Pullman, B.S., et al. (2020). The ProteomeXchange consortium in 2020: enabling 'big data' approaches in proteomics. Nucleic Acids Res. 48: D1145-D1152.

Dolmer, K., Campos, A., and Gettins, P.G. (2013). Quantitative dissection of the binding contributions of ligand lysines of the receptor-associated protein (RAP) to the low density lipoprotein receptor-related protein (LRP1). J. Biol. Chem. 288: 24081-24090.

Dunham, W.H., Mullin, M., and Gingras, A.C. (2012). Affinitypurification coupled to mass spectrometry: basic principles and strategies. Proteomics 12: 1576-1590.

Esko, J.D., J, H.P., and Linhardt, R.J. (2015). Proteins that bind sulfated glycosaminoglycans. In: Varki, A., Cummings, R.D., Esko, J.D., Stanley, P., Hart, G.W., Aebi, M., Darvill, A.G., Kinoshita, T., Packer, N.H., Prestegard, J.H., Schnaar, R.L., and Seeberger, P.H. (Eds.), Essentials of glycobiology, 3rd ed. Cold Spring Harbor Laboratory Press, New York pp. 493-502.

Fornerod, M., Ohno, M., Yoshida, M., and Mattaj, I.W. (1997). CRM1 is an export receptor for Leucine-Rich nuclear export signals. Cell 90: 1051-1060.

Furukawa, T., Ozawa, M., Huang, R.P., and Muramatsu, T. (1990). A heparin binding protein whose expression increases during differentiation of embryonal carcinoma cells to parietal endoderm cells: cDNA cloning and sequence analysis. J. Biochem. 108: 297-302.

Gandhi, N.S. and Mancera, R.L. (2008). The structure of glycosaminoglycans and their interactions with proteins. Chem. Biol. Drug Des. 72: 455-482.

Gaudet, P. and Dessimoz, C. (2017). Gene ontology: Pitfalls, biases, and remedies. In: Dessimoz, C., and Škunca, N. (Eds.), The gene ontology handbook. Springer, New York, NY pp. 189-205, https://doi.org/10.1007/978-1-4939-3743-1_14.

Gesslbauer, B., Derler, R., Handwerker, C., Seles, E., and Kungl, A.J. (2016). Exploring the glycosaminoglycan-protein interaction network by glycan-mediated pull-down proteomics. Electrophoresis 37: 1437-1447.

Green, N.M. (1975). Avidin. In: Advances in protein chemistry. Elsevier Inc., Amsterdam, pp. 85-133.

Gronbach, M., Mitrach, F., Lidzba, V., Muller, B., Moller, S., Rother, S., Salbach-Hirsch, J., Hofbauer, L.C., Schnabelrauch, M., Hintze, V., et al. (2020). Scavenging of Dickkopf-1 by macromerbased biomaterials covalently decorated with sulfated hyaluronan displays pro-osteogenic effects. Acta Biomater. 114: 76-89. 
Haji-Ghassemi, O., Muller-Loennies, S., Saldova, R., Muniyappa, M., Brade, L., Rudd, P.M., Harvey, D.J., Kosma, P., Brade, H., and Evans, S.V. (2014). Groove-type recognition of chlamydiaceaespecific lipopolysaccharide antigen by a family of antibodies possessing an unusual variable heavy chain $\mathrm{N}$-linked glycan. J. Biol. Chem. 289: 16644-16661.

Hempel, U., Moller, S., Noack, C., Hintze, V., Scharnweber, D., Schnabelrauch, M., and Dieter, P. (2012). Sulfated hyaluronan/ collagen I matrices enhance the osteogenic differentiation of human mesenchymal stromal cells in vitro even in the absence of dexamethasone. Acta Biomater. 8: 4064-4072.

Hempel, U., Matthaus, C., Preissler, C., Moller, S., Hintze, V., and Dieter, P. (2014a). Artificial matrices with high-sulfated glycosaminoglycans and collagen are anti-inflammatory and pro-osteogenic for human mesenchymal stromal cells. J. Cell. Biochem. 115: 1561-1571.

Hempel, U., Preissler, C., Vogel, S., Moller, S., Hintze, V., Becher, J., Schnabelrauch, M., Rauner, M., Hofbauer, L.C., and Dieter, P. (2014b). Artificial extracellular matrices with oversulfated glycosaminoglycan derivatives promote the differentiation of osteoblast-precursor cells and premature osteoblasts. Biomed Res. Int. 2014: 938368.

Hileman, R.E., Fromm, J.R., Weiler, J.M., and Linhardt, R.J. (1998). Glycosaminoglycan-protein interactions: definition of consensus sites in glycosaminoglycan binding proteins. Bioessays 20: 156-167.

Hintze, V., Moeller, S., Schnabelrauch, M., Bierbaum, S., Viola, M., Worch, H., and Scharnweber, D. (2009). Modifications of hyaluronan influence the interaction with human bone morphogenetic protein-4 (hBMP-4). Biomacromolecules 10: 3290-3297.

Huang Da, W., Sherman, B.T., and Lempicki, R.A. (2009). Systematic and integrative analysis of large gene lists using DAVID bioinformatics resources. Nat. Protoc. 4: 44-57.

Hughes, C.S., Moggridge, S., Muller, T., Sorensen, P.H., Morin, G.B., and Krijgsveld, J. (2019). Single-pot, solid-phase-enhanced sample preparation for proteomics experiments. Nat. Protoc. 14: 68-85.

Huttlin, E.L., Bruckner, R.J., Paulo, J.A., Cannon, J.R., Ting, L., Baltier, K., Colby, G., Gebreab, F., Gygi, M.P., Parzen, H., et al. (2017). Architecture of the human interactome defines protein communities and disease networks. Nature 545: 505-509.

Jouy, F., Muller, S.A., Wagner, J., Otto, W., Von Bergen, M., and Tomm, J.M. (2015). Integration of conventional quantitative and phospho-proteomics reveals new elements in activated Jurkat T-cell receptor pathway maintenance. Proteomics 15: 25-33.

Jouy, F., Lohmann, N., Wandel, E., Ruiz-Gomez, G., Pisabarro, M.T., Beck-Sickinger, A.G., Schnabelrauch, M., Moller, S., Simon, J.C., Kalkhof, S., et al. (2017). Sulfated hyaluronan attenuates inflammatory signaling pathways in macrophages involving induction of antioxidants. Proteomics 17: e1700082.

Kanekiyo, T., Zhang, J., Liu, Q., Liu, C.C., Zhang, L., and Bu, G. (2011). Heparan sulphate proteoglycan and the low-density lipoprotein receptor-related protein 1 constitute major pathways for neuronal amyloid-beta uptake. J. Neurosci. 31: 1644-1651.

Kliemt, S., Lange, C., Otto, W., Hintze, V., Moller, S., Von Bergen, M., Hempel, U., and Kalkhof, S. (2013). Sulfated hyaluronan containing collagen matrices enhance cell-matrix-interaction, endocytosis, and osteogenic differentiation of human mesenchymal stromal cells. J. Proteome Res. 12: 378-389.
Köhling, S., Exner, M.P., Nojoumi, S., Schiller, J., Budisa, N., and Rademann, J. (2016a). One-Pot synthesis of unprotected anomeric glycosyl thiols in water for glycan ligation reactions with highly functionalized sugars. Angew Chem. Int. Ed. Engl. 55: 15510-15514.

Köhling, S., Kunze, G., Lemmnitzer, K., Bermudez, M., Wolber, G., Schiller, J., Huster, D., and Rademann, J. (2016b). Chemoenzymatic synthesis of nonasulfated tetrahyaluronan with a paramagnetic tag for studying its complex with Interleukin-10. Chemistry 22: 5563-5574.

Köhling, S., Blaszkiewicz, J., Ruiz-Gomez, G., Fernandez-Bachiller, M.I., Lemmnitzer, K., Panitz, N., Beck-Sickinger, A.G., Schiller, J., Pisabarro, M.T., and Rademann, J. (2019). Syntheses of defined sulfated oligohyaluronans reveal structural effects, diversity and thermodynamics of GAG-protein binding. Chem. Sci. 10: 866-878.

Kowitsch, A., Zhou, G., and Groth, T. (2018). Medical application of glycosaminoglycans: a review. J. Tissue Eng. Regen. Med. 12: e23-e41.

Krieghoff, J., Picke, A.K., Salbach-Hirsch, J., Rother, S., Heinemann, C., Bernhardt, R., Kascholke, C., Moller, S., Rauner, M., Schnabelrauch, M., et al. (2019). Increased pore size of scaffolds improves coating efficiency with sulfated hyaluronan and mineralization capacity of osteoblasts. Biomater. Res. 23: 26.

Kunze, R., Rosler, M., Moller, S., Schnabelrauch, M., Riemer, T., Hempel, U., and Dieter, P. (2010). Sulfated hyaluronan derivatives reduce the proliferation rate of primary rat calvarial osteoblasts. Glycoconj. J. 27: 151-158.

Lalazar, A., Weisgraber, K.H., Rall, S.C., Jr., Giladi, H., Innerarity, T.L., Levanon, A.Z., Boyles, J.K., Amit, B., Gorecki, M., Mahley, R.W., et al. (1988). Site-specific mutagenesis of human apolipoprotein E. Receptor binding activity of variants with single amino acid substitutions. J. Biol. Chem. 263: 3542-3545.

Lillis, A.P., Van Duyn, L.B., Murphy-Ullrich, J.E., and Strickland, D.K. (2008). LDL receptor-related protein 1: unique tissue-specific functions revealed by selective gene knockout studies. Physiol. Rev. 88: 887-918.

Lipfert, J., Doniach, S., Das, R., and Herschlag, D. (2014). Understanding nucleic acid-ion interactions. Annu. Rev. Biochem. 83: 813-841.

Morrow, J.A., Arnold, K.S., Dong, J., Balestra, M.E., Innerarity, T.L., and Weisgraber, K.H. (2000). Effect of arginine 172 on the binding of apolipoprotein $\mathrm{E}$ to the low density lipoprotein receptor. J. Biol. Chem. 275: 2576-2580.

Nagahata, M., Tsuchiya, T., Ishiguro, T., Matsuda, N., Nakatsuchi, Y., Teramoto, A., Hachimori, A., and Abe, K. (2004). A novel function of $\mathrm{N}$-cadherin and Connexin43: marked enhancement of alkaline phosphatase activity in rat calvarial osteoblast exposed to sulfated hyaluronan. Biochem. Biophys. Res. Commun. 315: 603-611.

Oswald, J., Boxberger, S., Jorgensen, B., Feldmann, S., Ehninger, G., Bornhauser, M., and Werner, C. (2004). Mesenchymal stem cells can be differentiated into endothelial cells in vitro. Stem Cell. 22: 377-384.

Pourakbari, R., Khodadadi, M., Aghebati-Maleki, A., Aghebati-Maleki, L., and Yousefi, M. (2019). The potential of exosomes in the therapy of the cartilage and bone complications; emphasis on osteoarthritis. Life Sci. 236: 116861.

Purohit, S., Li, T., Guan, W., Song, X., Song, J., Tian, Y., Li, L., Sharma, A., Dun, B., Mysona, D., et al. (2018). Multiplex glycan bead array 
for high throughput and high content analyses of glycan binding proteins. Nat. Commun. 9: 258.

Rodenburg, K.W., Kjoller, L., Petersen, H.H., and Andreasen, P.A. (1998). Binding of urokinase-type plasminogen activatorplasminogen activator inhibitor-1 complex to the endocytosis receptors alpha2-macroglobulin receptor/low-density lipoprotein receptor-related protein and very-low-density lipoprotein receptor involves basic residues in the inhibitor. Biochem. J. 329: 55-63.

Rother, S., Samsonov, S.A., Hempel, U., Vogel, S., Moeller, S., Blaszkiewicz, J., Köhling, S., Schnabelrauch, M., Rademann, J., Pisabarro, M.T., et al. (2016). Sulfated hyaluronan alters the interaction profile of TIMP-3 with the endocytic receptor LRP-1 clusters II and IV and increases the extracellular TIMP-3 level of human bone marrow stromal cells. Biomacromolecules 17: 3252-3261.

Ruiz-Gómez, G., Vogel, S., Möller, S., Pisabarro, M.T., and Hempel, U. (2019). Glycosaminoglycans influence enzyme activity of MMP2 and MMP2/TIMP3 complex formation - insights at cellular and molecular level. Sci. Rep. 9, https://doi.org/10.1038/s41598019-41355-2.

Sachchidanand, Lequin, O., Staunton, D., Mulloy, B., Forster, M.J., Yoshida, K., and Campbell, I.D. (2002). Mapping the heparinbinding site on the 13-14F3 fragment of fibronectin. J. Biol. Chem. 277: 50629-50635.

Salbach, J., Rachner, T.D., Rauner, M., Hempel, U., Anderegg, U., Franz, S., Simon, J.C., and Hofbauer, L.C. (2012). Regenerative potential of glycosaminoglycans for skin and bone. J. Mol. Med. 90: 625-635.

Salbach-Hirsch, J., Ziegler, N., Thiele, S., Moeller, S., Schnabelrauch, M., Hintze, V., Scharnweber, D., Rauner, M., and Hofbauer, L.C. (2014). Sulfated glycosaminoglycans support osteoblast functions and concurrently suppress osteoclasts. J. Cell. Biochem. 115: 1101-1111.

Salbach-Hirsch, J., Samsonov, S.A., Hintze, V., Hofbauer, C., Picke, A.K., Rauner, M., Gehrcke, J.P., Moeller, S., Schnabelrauch, M., Scharnweber, D., et al. (2015). Structural and functional insights into sclerostin-glycosaminoglycan interactions in bone. Biomaterials 67: 335-345.

Scharnweber, D., Hubner, L., Rother, S., Hempel, U., Anderegg, U., Samsonov, S.A., Pisabarro, M.T., Hofbauer, L., Schnabelrauch, M., Franz, S., et al. (2015). Glycosaminoglycan derivatives: promising candidates for the design of functional biomaterials. J. Mater. Sci. Mater. Med. 26: 232.

Schmidt, J.R., Kliemt, S., Preissler, C., Moeller, S., Von Bergen, M., Hempel, U., and Kalkhof, S. (2016). Osteoblast-released matrix vesicles, regulation of activity and composition by sulfated and non-sulfated glycosaminoglycans. Mol. Cell. Proteomics 15: 558-572.

Schmidt, J.R., Vogel, S., Moeller, S., Kalkhof, S., Schubert, K., Von Bergen, M., and Hempel, U. (2018). Sulfated hyaluronic acid and dexamethasone possess a synergistic potential in the differentiation of osteoblasts from human bone marrow stromal cells. J. Cell. Biochem. 120: 8706-8722.

Shipp, E.L. and Hsieh-Wilson, L.C. (2007). Profiling the sulfation specificities of glycosaminoglycan interactions with growth factors and chemotactic proteins using microarrays. Chem. Biol. 14: 195-208.

Szklarczyk, D., Gable, A.L., Lyon, D., Junge, A., Wyder, S., HuertaCepas, J., Simonovic, M., Doncheva, N.T., Morris, J.H., Bork, P., et al. (2019). STRING v11: protein-protein association networks with increased coverage, supporting functional discovery in genome-wide experimental datasets. Nucleic Acids Res. 47: D607-D613.

The Gene Ontology Consortium (2019). The gene ontology resource: 20 years and still GOing strong. Nucleic Acids Res. 47: D330-D338.

Tsourdi, E., Salbach-Hirsch, J., Rauner, M., Rachner, T.D., Möller, S., Schnabelrauch, M., Scharnweber, D., and Hofbauer, L.C. (2014). Glycosaminoglycans and their sulfate derivatives differentially regulate the viability and gene expression of osteocyte-like cell lines. J. Bioact. Compat Polym. 29: 474-485.

Uniprot, C. (2019). UniProt: a worldwide hub of protein knowledge. Nucleic Acids Res. 47: D506-D515.

Vallet, S.D., Clerc, O., and Ricard-Blum, S. (2021). Glycosaminoglycanprotein interactions: the first draft of the glycosaminoglycan interactome. J. Histochem. Cytochem. 69: 93-104.

Vogel, S., Arnoldini, S., Moller, S., Schnabelrauch, M., and Hempel, U. (2016). Sulfated hyaluronan alters fibronectin matrix assembly and promotes osteogenic differentiation of human bone marrow stromal cells. Sci. Rep. 6: 36418.

Williams, S.E., Ashcom, J.D., Argraves, W.S., and Strickland, D.K. (1992). A novel mechanism for controlling the activity of alpha 2-macroglobulin receptor/low density lipoprotein receptorrelated protein. Multiple regulatory sites for $39-\mathrm{kDa}$ receptorassociated protein. J. Biol. Chem. 267: 9035-9040.

Yan, C., Terribilini, M., Wu, F., Jernigan, R.L., Dobbs, D., and Honavar, V. (2006). Predicting DNA-binding sites of proteins from amino acid sequence. BMC Bioinf. 7: 262.

Supplementary Material: The online version of this article offers supplementary material (https://doi.org/10.1515/hsz-2021-0167). 